high-quality higher education locally, to prevent high levels of student migration in the first place. This is the sort of recent expansion and capacity building seen in both China and India. Second, countries are also offering incentives for their foreign-educated talent to return home; one analysis suggests that there are at least I8 countries with programs designed to attract expatriates. The third group of engagement and network strategies is based on the recognition that highly educated and qualified individuals settled overseas can be engaged through diaspora networks and other initiatives that may ultimately benefit their home country and allow them to contribute, albeit from a distance.

What can receiving countries do? First, at the national level, scholarships offered by host countries are an enduring mechanism to increase access not only for students from poorer countries, but also for marginalized and underrepresented students within those countries-such scholarships are now being monitored through target 4.b of the Sustainable Development Goals (SDGs). Second, institutions should not only diversify the countries from which they recruit international students, but should also pay more attention to how they can increase access for potential international students who might not have the means or know-how to access a global education opportunity. Finally, more can be done at the institutional and national levels in major destination countries, to foster international networks and collaborations that enable their international students and immigrant/diaspora faculty to connect with their peers in their home countries.

The field of student mobility today is going through a period of reflection and stocktaking, primarily due to an altered political and social landscape. It is therefore timely to revisit and examine the fundamental ethics, assumptions, and power dynamics that underpin student mobility: how do we ensure that the mobility of students and talent is based on principles of access, equity, and inclusiveness, both at the student level and at the national level? The SDGs have also brought a renewed focus to these issues. Lastly, there are some key gaps in data and knowledge that also need to be addressed. Not enough is known about the socioeconomic background of students who participate in a mobility experience. More concrete measurements are needed of which type of students leave their countries and how this impacts the future talent pools of both home and host countries. And given that there will always be larger outflows of students and talent from the Global South, we need to develop more meaningful and nuanced measures of how skilled immigrants and diaspora communities continue to contribute to their home countries through fostering international collaborations and networks-multiplier effects that go beyond simplistic (albeit critical) financial measures such as remittances.

\section{Rankings and the Public Good Role of Higher Education}

\section{Ellen Hazelkorn}

Ellen Hazelkorn is professor emerita and director, Higher Education Policy Research Unit, Dublin Institute of Technology, Ireland, and partner, BH Associates, Education Consultants. E-mail: ellen.hazelkorn@ dit.ie.

$\mathrm{O}$ ne of the most prominent issues of public and political concern today is the extent to which universities contribute to the public good. Universities have historically had a close relationship with the city and country of their founding. Yet, today, they are often considered part of the elite. Student learning and graduate outcomes are often discounted in preference to pursuing global reputation.

Unequal distribution of societal goods has spurred a deep sense of grievance as evidenced by recent elections and political turmoil around the world. The recent scandal in the United States about financial payments to enable back-door entry to elite universities highlights intensifying social stratification while also raising fundamental questions about the role and responsibilities of universities. These issues are framing the background around increased attention and monitoring of universities. This has placed them under pressure to contribute more to their communities and regions, work with business and civil society, and demonstrate how well they do this.

Rankings have portrayed themselves as promoting greater public information and disclosure, comparing performance internationally to inform students/parents, governments, and the wider public. But too often, rankings measure benefits gained from accumulated public and/or private wealth and investment over decades if not centuries. Their choice of indicators cherish the benefits of attracting high achieving/high socioeconomic students who graduate on time and go on to have successful careers. Excellence is measured in terms of achievements of individual universities rather than public good to society collectively. These factors are reproduced in the indicators that rankings use and popularize. 


\section{RAN KINGS AND SOCIETAL IMPACT}

Aiming to respond to criticism and broaden their appealand their product range-rankings have begun to measure universities' societal commitment. Times Higher Education (THE) and QS have historically measured society engagement in terms of research collaboration or third-party/ industry earned income. This is interpreted as a proxy for knowledge transfer and relies entirely on institutional data. ARWU uses traditional research indicators and has not strayed from this approach. In contrast, U-Multirank has always used a broader range of indicators. Regional engagement is measured as student internships, graduate employment, and engagement with regional organizations, while knowledge transfer is measured as collaboration with industry, patents/spinoffs, and copublications with industry. It also uses institutional data, and switches between numbers and percentages. Greenmetric World University Ranking was launched in 2010. Managed by Universitas Indonesia, it compares "the commitment of universities towards going green and promoting sustainable operation." It suffers from the shortcomings of institutional data, but in the era of increased public awareness of climate change, it has begun to gain some traction. Not surprisingly, THE and QS are also embracing societal impact.

\section{The European Union has sponsored several initiatives seeking to capture en- gagement with/impact on civil society.}

QS includes social responsibility within its QS Stars Ranking. It assesses how far a university takes its obligations to society seriously by supporting the local community and environment awareness. Indicators include community investment and development, charity work and disaster relief, regional human capital, and environmental impact. The first two groupings measure commitment in terms of financial contributions of I percent of turnover or US\$2 million; the latter two include student recruitment and graduate employment in the region, and sustainability actions. THE launched its University Impact Ranking in April 2019 to great fanfare. It measures activity aligned with the II of the I7 UN Sustainability Development Goals (SDGs). Universities must provide data for SDG No. I7collaboration with other countries, promotion of best practices, and the publication of data-plus at least three other SDGs of their choice. This enables universities to differentiate themselves and play to their strengths. Each SDG field includes a myriad indicators, but research activity accounts for 27 percent in each of them. This makes it difficult for new/young or nonresearch universities to make an impact. With the exception of research data from Elsevier, universities provide all the evidence and examples. Not only is this a lot of work but, sad to say, institutional data or commentary is not reliable. Some 556 institutions submitted data on one or more of the SDGs, and I4I institutions (25 percent) submitted data on the II SDGs that feature in the ranking.

\section{Alternative Approaches}

There are other less familiar rankings, plus a growing number of government efforts, that are seeking and displaying comparative information around public good. Most notable is the Washington Monthly's College Guide and Rankings, which adapts a JFK saying: "While other guides ask what colleges can do for students, we ask what colleges are doing for the country." It believes universities should be assessed as engines of social mobility, supporting academic minds and scientific research that advance knowledge and drive economic growth, and inculcating/encouraging an ethic of service. It has also developed a ranking of community colleges. An older example is the Saviors of Our Cities: Survey of Best College and University Civic Partnerships, which measures "the positive economic, social, and cultural impact that institutions of higher education have upon the cities in which they reside." It was followed by Metroversity Ranking. America's Best College Buys was originally published by Money in I990; it is now published by Forbes as America's Best Value Colleges. It analyzes "how much a college should be expected to cost based on a number of factors." Similarly, Washington Monthly created the Bangfor-the-Buck College Rankings.

Governments are asking similar questions. Concerns about student performance, affordability, and graduate success, alongside public/community engagement, have spurred considerable action around the world. These instruments are less concerned with rankings and more about accountability. Under the Obama administration, the US government linked access, affordability, and outcomes in a single tool called the College Scorecard. This is now being extended to place greater focus on individual programs rather than institutions. The United Kingdom has created the Teaching Excellence Framework (TEF) and the Knowledge Exchange Framework (KEF). The European Union has sponsored several initiatives seeking to capture engagement with/impact on civil society. In recent weeks, the Bill and Melinda Gates Foundation established the PostSecondary Value Commission to gauge how well universities create value for students and contribute to economic opportunity for students. 


\section{Driving Behavior-But in What Direction?}

Instruments that raise wider questions about university public good are welcome. However, most effort is about economic impacts-how higher education meets the objectives of effectiveness, equity, and efficiency-rather than wider societal impact. This is partially because measuring cultural and societal impact or the value to public discourse through new ideas etc. is complicated. Yet, soft power, expressed through contribution to cultural institutions, democracy, international understanding, and overall society's value systems and policies, is equally powerful and can significantly influence a country's international standing with mobile investment and talent.

No doubt rankings drive behavior, but the direction of travel depends upon the choice of indicators. Governments and universities are not innocent victims: they have too often slavishly changed their policies and priorities to rise in the rankings for fear of falling behind their neighbor or competitor. BUT do the ranking organizations themselves bear any responsibility given that their real intent is to sell magazines and newspapers and/or consultancy? Indeed, despite their calls for greater transparency and accountability, their methodologies display very little. It is no longer good enough to only talk about universities' corporate social responsibility. Isn't it time we talked about the corporate social responsibility of the ranking organizations themselves?

\section{Religion, a Major Driver for Forced Internationalization}

\section{Hakan Ergin and Hans de Wit}

Hakan Ergin is a former postdoctoral scholar at the Center for International Higher Education (CIHE), Boston College, US, and a lecturer at Istanbul University, Turkey.E-mail: hakan.ergin1@yahoo.com. Hans de Wit is director of CIHE, Boston College, US. E-mail: dewitj@bc.edu.

I $\mathrm{n}$ an article published in $\mathrm{IHE}$ \#97, "Forced Internationalization of Higher Education," the authors and Betty Leask show how policy makers can be "forced" to internationalize their higher education systems as a result of massive and unexpected arrivals of refugees (in today's world, 68.5 million people have become forced migrants-the largest forced displacement since the World War II according to the United Nations High Commissioner for Refugees, UNHCR). While regular international students or scholars arrive equipped with sufficient sponsorship, well-document- ed academic credentials, and foreign language proficiency, the drivers through which refugees access higher education in their host countries are untraditional. This article discusses how religion has become a strong driver for Syrian refugees' access to higher education in Turkey.

\section{Religious Motivation}

Adopting an "open door" policy for people fleeing the conflict in Syria, Turkey is currently host to over 3.6 million Syrian refugees according to the UNHCR. The unceasing conflict in Syria and extended stay of the refugees in Turkey have "forced" the Turkish government to strategically internationalize higher education to ensure the "unexpected" and "seemingly permanent" Syrian refugees' access to universities.

First, no "selective" and "restrictive" credential evaluation procedure is taking place. While some of the universities admit Syrian refugees based on their secondary or (interrupted) postsecondary education's grade point average, others admit them without any requirement. Next, in order to overcome the language barrier, a free preparatory oneyear Turkish language program is offered, and several universities have established study programs taught in Arabic.

\section{Adopting an "open door" policy for peo- ple fleeing the conflict in Syria, Turkey is currently host to over 3.6 million Syrian refugees according to the UNHCR.}

Last, Syrian students are exempt from paying tuition fees and provided with governmental scholarships. According to the Council of Higher Education (CoHE), these reforms have resulted in over 27,000 Syrian refugees enrolling in universities, which has made Turkey one of the countries hosting the highest number of refugee students in the world.

Getting into a university is highly competitive for domestic students in Turkey. Every summer, over two million candidates sit the university entrance test and very few can find a place at top public universities. Most have to enroll in private universities or in open education programs, or to resit the test the following year. In such a competitive context, the driver securing privileged access to Syrian refugees is based on a religious doctrine, the "Hegira."

According to the Islamic belief, the Hegira is the forced migration of Prophet Muhammad from Mecca to Medina in 622 as a result of persecutions by local people in Mec- 